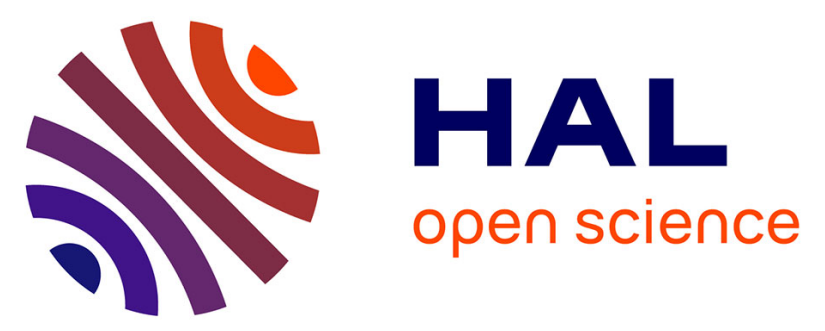

\title{
Cementite-free martensitic steels: A new route to develop high strength/high toughness grades by modifying the conventional precipitation sequence during tempering
}

Denis Delagnes, Florence Pettinari-Sturmel, M. H. Mathon, R. Danoix, F. Danoix, Cédric Bellot, Pascal Lamesle, A. Grellier

\section{To cite this version:}

Denis Delagnes, Florence Pettinari-Sturmel, M. H. Mathon, R. Danoix, F. Danoix, et al.. Cementitefree martensitic steels: A new route to develop high strength/high toughness grades by modifying the conventional precipitation sequence during tempering. Acta Materialia, 2012, 60 (16), pp.5877-5888. 10.1016/j.actamat.2012.07.030 . hal-01687325

\section{HAL Id: hal-01687325 \\ https://hal.science/hal-01687325}

Submitted on 15 Mar 2019

HAL is a multi-disciplinary open access archive for the deposit and dissemination of scientific research documents, whether they are published or not. The documents may come from teaching and research institutions in France or abroad, or from public or private research centers.
L'archive ouverte pluridisciplinaire HAL, est destinée au dépôt et à la diffusion de documents scientifiques de niveau recherche, publiés ou non, émanant des établissements d'enseignement et de recherche français ou étrangers, des laboratoires publics ou privés. 


\title{
Cementite-free martensitic steels: A new route to develop high strength/high toughness grades by modifying the conventional precipitation sequence during tempering
}

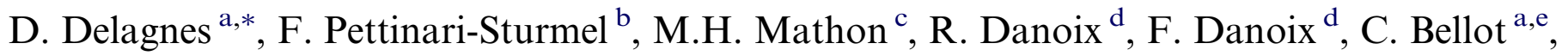 \\ P. Lamesle ${ }^{\mathrm{a}}$, A. Grellier ${ }^{\mathrm{e}}$ \\ ${ }^{a}$ Université de Toulouse, Mines Albi, Institut Clément Ader, Campus Jarlard, F-81013 Albi Cedex 09, France \\ ${ }^{\mathrm{b}}$ Centre d'Elaboration des Matériaux et d'Etudes Structurales, CNRS, 29 Rue Jeanne Marvig, B.P. 94347, F-31055 Toulouse Cedex 4, France \\ ${ }^{\mathrm{c}}$ Laboratoire Léon Brillouin (CEA-CNRS), CEA Saclay, F-91191 Gif-sur-Yvette, France \\ ${ }^{\mathrm{d}}$ Groupe de Physique des Matériaux, UMR CNRS 6634, Institut des Matériaux de Rouen, Université de Rouen, Avenue de l'Université, \\ B.P. 12, F-76801 Saint Etienne du Rouvray Cedex, France \\ e Aubert \& Duval, Parc Technologique La Pardieu, 6 Rue Condorcet, F-63063 Clermont-Ferrand Cedex 1, France
}

\begin{abstract}
Aluminium was added to a $0.2 \% \mathrm{C}-2.5 \% \mathrm{Cr}-1.4 \% \mathrm{Mo}-11 \% \mathrm{Ni}$ steel to modify the precipitation sequence during tempering treatment. The main goal was to obtain fine co-precipitation of an intermetallic phase and $\mathrm{M}_{2} \mathrm{C}$ carbides (where $\mathrm{M}$ is a combination of $\mathrm{Cr}$, $\mathrm{Mo}$ and small amounts of $\mathrm{Fe}$ ). Small angle neutron scattering, synchrotron X-ray diffraction, transmission electron microscopy and atom probe tomography were performed to characterize the nanometric precipitation. The tempering response of samples austenitized at $900{ }^{\circ} \mathrm{C}$ revealed a strong interaction between the two types of precipitation, leading to a significant modification of both the precipitation sequence of carbides and the arrangement of carbide nucleation sites compared with these sites in a single precipitation steel. Indeed, a microstructural investigation clearly showed that iron carbide precipitation was either delayed or did not occur during the tempering process, depending of the alloying elements added. Moreover, double precipitation directly influenced the mechanical resistance, as well as the toughness, leading to an ultrahigh-strength, high toughness steel.
\end{abstract}

Keywords: Martensitic steels; Iron carbides; $\beta$-NiFeAl particles; $\mathrm{M}_{2} \mathrm{C}$ secondary carbides; Ultimate tensile strength-fracture toughness balance

\section{Introduction}

In answer to the need to reduce energy consumption and reduce carbon dioxide emissions the transport industry, particularly the aeronautics sector, requires the development of new, high performance steels combining high mechanical resistance as well as improved toughness. The main objectives of weight reduction, structural durability and aircraft safety underpin continued research activities into high strength steels. This research is also driven by

\footnotetext{
* Corresponding author. Tel.: +33 (0) 5634932 48; fax: +33(0) 563493242. E-mail address: delagnes@enstimac.fr (D. Delagnes).
}

considerations of economy in manufacture. Nearly two decades ago American researchers and industrialists first succeeded in producing steels with higher mechanical properties by producing a microstructure strengthened by double precipitation of nanometric scale carbides and intermetallic phases [1,2]. More recently the same concept was used by Austrian teams to develop new steels for application as hot work tools [3]. This idea has probably opened up a new generation of steels.

The first criterion in classifying steels according to their performance is the ratio of toughness to tensile strength. This is usually represented by a diagram which is well adapted to aeronautical applications. As shown in Fig. 1, 


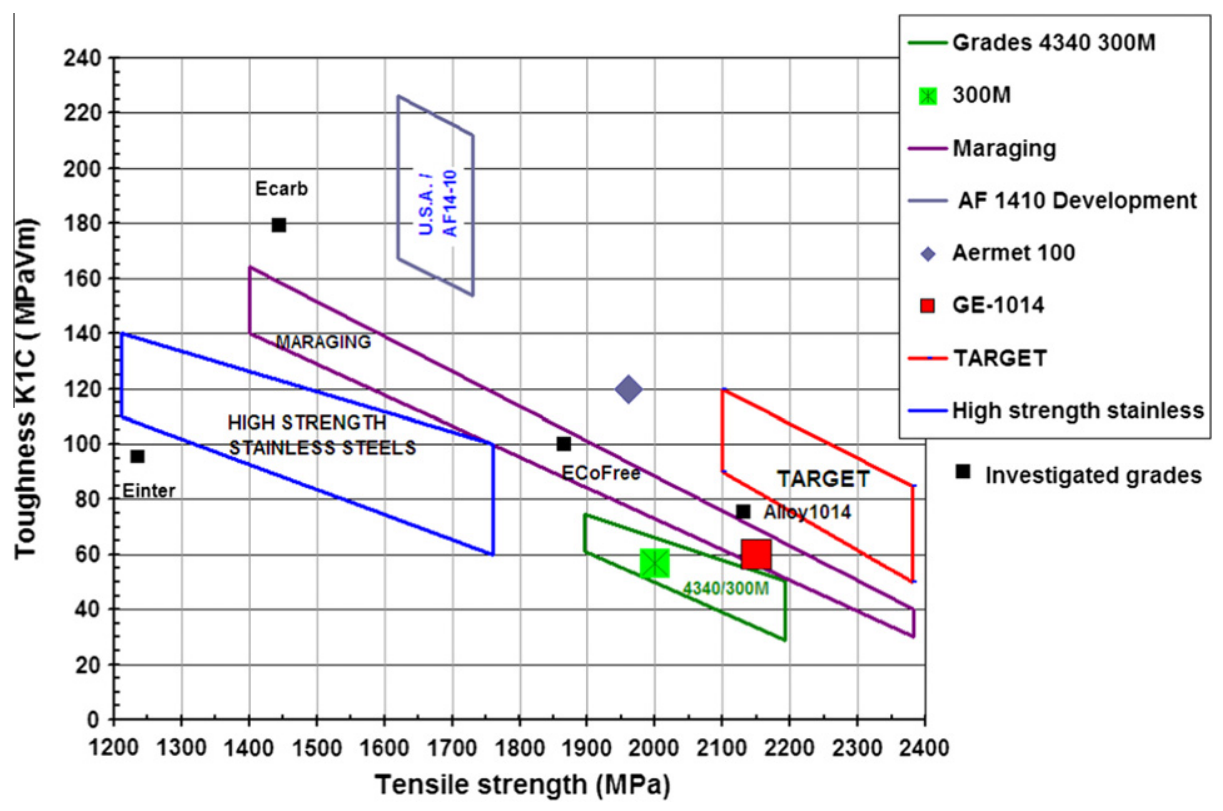

Fig. 1. Toughness-tensile strength diagram for several standard steels used in aeronautical applications (from Olson [4,5]).

taken from Olson [4,5], the conventional steel $300 \mathrm{M}$ (ultimate tensile strength (UTS) $2000 \mathrm{MPa}$ and a fracture toughness $\left(K_{\mathrm{Ic}}\right)$ of $\left.60 \mathrm{MPa} \sqrt{\mathrm{m}}\right)$ hardened with secondary carbides containing chromium, vanadium and molybdenum is still the reference. For 40 years this steel has been widely used for the landing gear of civil aircraft. For two decades (1950-1970) intensive research programs for space applications led to the development of maraging steels, which presented a better balance of properties, but at a higher cost. These steels are carbon free and hardened by intermetallic phases such as $\mathrm{Ni}_{3} \mathrm{Mo}$ and $\mathrm{Ni}_{3} \mathrm{Ti}$. Since the end of the 1970s, a first generation of new steels hardened with very fine precipitates of molybdenum carbides $\mathrm{Mo}_{2} \mathrm{C}$ have been developed in the USA and sold under the trademarks AF1410 and AERMET 100 steels [6,7]. The best balance at this time seems to have been reached by the more recently developed AERMET 340 [8], providing a UTS of about $2344 \mathrm{MPa}$ and a $K_{\text {Ic }}$ of $65 \mathrm{MPa} \sqrt{\mathrm{m}}$. Then, from the AERMET nominal chemical composition (about $0.2-0.3 \% \mathrm{C}, 2.2 \% \mathrm{Cr}, 2 \% \mathrm{Mo}$ with large quantities of $\mathrm{Ni}$ and Co), GE1014 steel, strengthened by a double nanometric precipitation of intermetallic phase and carbides, was developed from the considerable work of Garrison et al. $[1,9,10]$. GE1014 steel is characterized by both the presence of intermetallic strengthening precipitates, as in maraging steels, and by alloy carbide strengtheners, as commonly found in secondary hardening steels. Titanium is absent from the composition to avoid the formation of non-metallic inclusions, such as titanium carbonitrides, which correspondingly enhances the fatigue properties. This allowed the development of the fan mid-shaft of the new GE90 engines (General Electric Aircraft Engines). Although the balance of properties is not so different from conventional steels (Fig. 1), it is possible to work at elevated temperatures reaching $400{ }^{\circ} \mathrm{C}$, which is not tolerated by $300 \mathrm{M}$ steel. On the other hand, the fatigue properties are enhanced compared with those of Maraging 250 and 300.

Although the duplex strengthening route gives outstanding mechanical properties and relevant microstructural investigations have already been performed $[3,11]$, the complex mechanisms involved in the different stages of precipitation are still imprecise or unknown. Consequently, scientific arguments attempting to explain the improvements still need to be clarified. Indeed, multi-scale investigations of the microstructure, including the need to use advanced experimental techniques, are absolutely essential to direct the future development of steel composition. This is the main goal of the present study.

\section{Experiments}

\subsection{Materials}

In order to investigate the interactions between the two types of precipitation, different grades were prepared containing a single precipitate (only carbides or only intermetallic) or double precipitates.

The chemical compositions of the grades investigated are given in Table 1. The reference, Alloy1014 steel, has the same composition as GE1014 steel. Each experimental grade was derived from the reference by removing cobalt only (Ecofree grade) or cobalt and one type of precipitate:

Table 1

Chemical composition (wt.\%) of the grades under investigation.

\begin{tabular}{llllrrr}
\hline Grade & $\mathrm{C}$ & $\mathrm{Ni}$ & $\mathrm{Cr}$ & \multicolumn{1}{c}{ Mo } & \multicolumn{1}{c}{$\mathrm{Al}$} & \multicolumn{1}{c}{ Co } \\
\hline Alloy1014 & 0.23 & 13.90 & 2.30 & 1.48 & 0.89 & 10.00 \\
Ecarb & 0.21 & 10.49 & 2.39 & 1.40 & $<0.01$ & $<0.02$ \\
Einter & 0.017 & 11.73 & 2.38 & $<0.01$ & 1.05 & $<0.02$ \\
Ecofree & 0.21 & 11.45 & 2.39 & 1.49 & 1.10 & $<0.02$ \\
\hline
\end{tabular}


Ecarb (aluminium free) and Einter (carbon and molybdenum free).

ThermoCalc ${ }^{\circledR}$ software giving the equilibrium phase diagram was used to adapt the chemical composition of each experimental grade, taking into account that austenite, the $\mathrm{M}_{2} \mathrm{C}$ carbides and the intermetallic phase contents should be equivalent for all grades considered at equilibrium. For instance, as the Ecarb grade contains no aluminium to prevent intermetallic phase formation, the excess nickel tends to form austenite instead of ferrite. To eliminate this undesirable effect the nickel content was decreased from that in the reference. X-ray diffraction experiments and microscopy observations were performed to check whether the adopted criterion was correct.

The same heat treatment for all grades comprised austenitizing at $900^{\circ} \mathrm{C}$ for $1 \mathrm{~h}$, cryogenic quenching at $-80{ }^{\circ} \mathrm{C}$ for $8 \mathrm{~h}$ (no retained austenite detected), followed by double tempering. The first tempering operation was performed at $200{ }^{\circ} \mathrm{C}$ for $8 \mathrm{~h}$, the second at $500{ }^{\circ} \mathrm{C}$. Different samples were prepared to investigate the precipitation kinetics with eight different tempering times from $10 \mathrm{~min}$ to $1000 \mathrm{~h}$. Samples obtained after this treatment underwent microstructural investigations and mechanical tests. With the aim of clarifying the precipitation mechanisms, some specimens were also prepared that were only subjected to a temperature ramp of $0.2^{\circ} \mathrm{C} \mathrm{s}^{-1}$ from room temperature to $200{ }^{\circ} \mathrm{C}, 300{ }^{\circ} \mathrm{C}, 400{ }^{\circ} \mathrm{C}$ or $500{ }^{\circ} \mathrm{C}$ (followed by air quenching). Specimens were also prepared that underwent the first tempering stage (at $200{ }^{\circ} \mathrm{C}$ ) and were then subjected to the temperature ramp treatment. For all the grades investigated the microstructure was almost fully tempered martensite (the volume fraction of reverted austenite did not exceed $2 \%$ after $10 \mathrm{~h}$ tempering at $500{ }^{\circ} \mathrm{C}$ ).

\subsection{Experimental techniques}

Tensile tests and toughness experiments were performed at room temperature and carried out in a $250 \mathrm{kN}$ closed loop servo-hydraulic testing machine. The complete experimental set-up is presented in Zhang et al. [12]. For tensile tests the axial strain was measured with a $10 \mathrm{~mm}$ gauge length extensometer. Toughness experiments were carried out using normalized compact tension specimens, as described in Souki et al. [13].

The tempered martensitic microstructure was investigated by transmission electron microscopy (TEM) combined with selected area electron diffraction (SAED) in the CEMES-CNRS laboratories. Conventional as well as synchrotron X-ray diffraction (XRD) analysis was performed at the European Synchrotron Radiation Facility (ESRF) in Grenoble. Small angle neutron scattering (SANS) analysis was carried out at the Léon Brillouin Laboratory (LLB), while atom probe tomography (APT) was performed at the Institut des Matériaux de Rouen.

To determine the crystallographic structure by conventional XRD carbides were first extracted from the martensitic matrix using the dissolution technique described in Kim et al. [14]. XRD experiments were performed using a PANalytical X'Pert PRO diffractometer equipped with a $\mathrm{Cu} K_{\alpha}$ radiation source and a graphite crystal monochromator and scintillation counter.

The microstructure (the crystallographic characteristics of the matrix and the precipitates and the size and chemical composition of the precipitates) was investigated using different TEM techniques: conventional bright field and dark field observations, electron energy loss spectroscopy (EELS) experiments and high resolution electron microscopy (HREM) observations were performed using, respectively, a JEOL 2010, a FEI CM20-FEG, and a FEISACTEM (Tecnai F20) equipped with a spherical aberration corrector, all operating at $200 \mathrm{kV}$. To minimize the ferromagnetism effect, the volume of the TEM samples was reduced to a minimum, as the surface of a sample should not exceed $1 \mathrm{~mm}^{2}$ for an initial thickness of about $0.5 \mathrm{~mm}$. The samples were ground, mechanically polished and then thinned down by twin-jet electropolishing using a solution containing ethanol and butoxyethanol.

To obtain better statistics on the size distribution as well as the volume fraction of precipitates, SANS experiments were performed for all grades and heat treatment conditions. Two different experimental conditions were used: the wavelength $\lambda$ was fixed at 0.6 or $0.9 \mathrm{~nm}$, while the sample to detector distance $(D)$ was fixed at 2 or $5 \mathrm{~m}$, covering a scattering vector $(q)$ range of $0.05-1.6 \mathrm{~nm}^{-1}(q=4 \pi \sin \theta / \lambda$, where $2 \theta$ is the scattering angle, the $q$ range corresponding to the overlap of the two experimental conditions). Measurements were performed at room temperature, under a saturating magnetic field $H=1.7 \mathrm{~T}$ perpendicular to the incident neutron beam direction, in order to separate magnetic and nuclear scattering cross-sections. The measured intensities were corrected using standard computer programs developed in the LLB laboratory for sample transmission, background intensity and detector response [15]. The analysis method has already been reported [16-18].

For multiphase precipitation processes leading to the coexistence of different types of particles with different chemical compositions the chemical compositions of neither each type of precipitate nor the martensitic matrix can be obtained by SANS experiments, as several hypotheses may emerge from the data. Experimental data are therefore required on the composition profiles for each alloying element near the precipitate/matrix interface to give a better understanding of the mechanisms involved during nucleation and growth. Consequently, field ion microscopy (FIM) and atom probe tomography (APT) were used, as described in detail in Vurpillot et al. [19], Da Costa et al. [20] and Danoix et al. [21].

\section{Results}

\subsection{Mechanical properties}

Fig. 1 shows the positions of the four grades investigated among the different steels devoted to aeronautical 


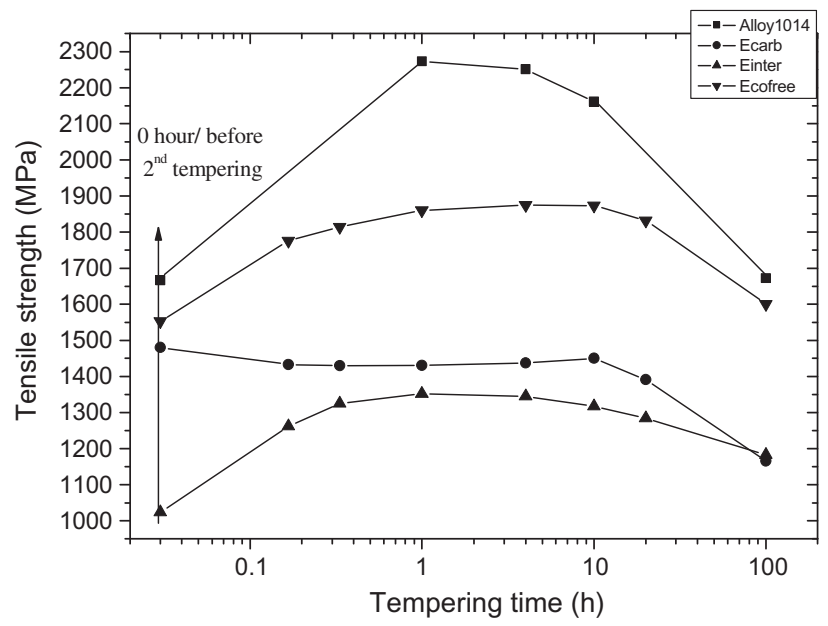

Fig. 2. Tensile strength with tempering time at $500{ }^{\circ} \mathrm{C}$.

applications in the toughness/tensile strength diagram. Room temperature ultimate tensile strengths, for a tempering time at $500{ }^{\circ} \mathrm{C}$, are presented in Fig. 2. From these two diagrams several main conclusions can be drawn.

- Alloy1014 has a tensile strength higher than all the experimental grades, probably due to the aluminium, molybdenum and cobalt contents.

- The Ecofree grade has a higher tensile strength compared with both the Ecarb and Einter grades, leading to the hypothesis that the two types of precipitation are involved in secondary hardening of the steel. This particular point is discussed below.

- The Einter grade has the poorest balance of properties. While the toughness is very close to that of the Ecofree and Alloy1014 grades, the tensile strength is lower. However, this is not unexpected, considering the fact that the latter property approximately reaches the maximum tensile strength measured in low carbon martensitic stainless steels containing $\beta-\mathrm{NiAl}$ particles $[22,23]$.

- Alloy1014 has the best balance of properties after treatment for $4 \mathrm{~h}$, which is close to the optimal duration of treatment, whereas the Ecofree grade presents the best balance at above $10 \mathrm{~h}$. This effect could be correlated with the addition of cobalt, which seems to shorten the tempering process.

For all the investigated grades the tensile strength reached before the second tempering was of the same order of magnitude, when compared with the maximum value (Fig. 2). Moreover, the major part of the gap between the maximum value and that obtained after the first tempering was filled in the first $10 \mathrm{~min}$ of tempering at $500{ }^{\circ} \mathrm{C}$, in spite of the recovery process. Consequently, the different mechanisms occurring during tempering, including precipitation, seem to start very quickly in the early stages of treatment, as described below.

\subsection{Precipitation sequence and kinetics: chemical composition and number density of particles with tempering time}

The precipitation sequence and kinetics during tempering were determined by SANS and APT for every tempering time from $10 \mathrm{~min}$ to $100 \mathrm{~h}$. XRD and electron diffraction were also performed to determine the crystallographic structure of the particles. For durations greater than $10 \mathrm{~h}$ the hexagonal $(\mathrm{MoCr})_{2} \mathrm{C}$ structure was detected in the Alloy1014, Ecofree and Ecarb grades (Figs. 3 and 4). The measured crystallographic parameters are $a=2.87 \AA$ and $c=4.53 \AA$, which means that they lie between the $\mathrm{Cr}_{2} \mathrm{C}$ and $\mathrm{Mo}_{2} \mathrm{C}$ carbide parameters. $\mathrm{M}_{3} \mathrm{C}$ carbides containing large amounts

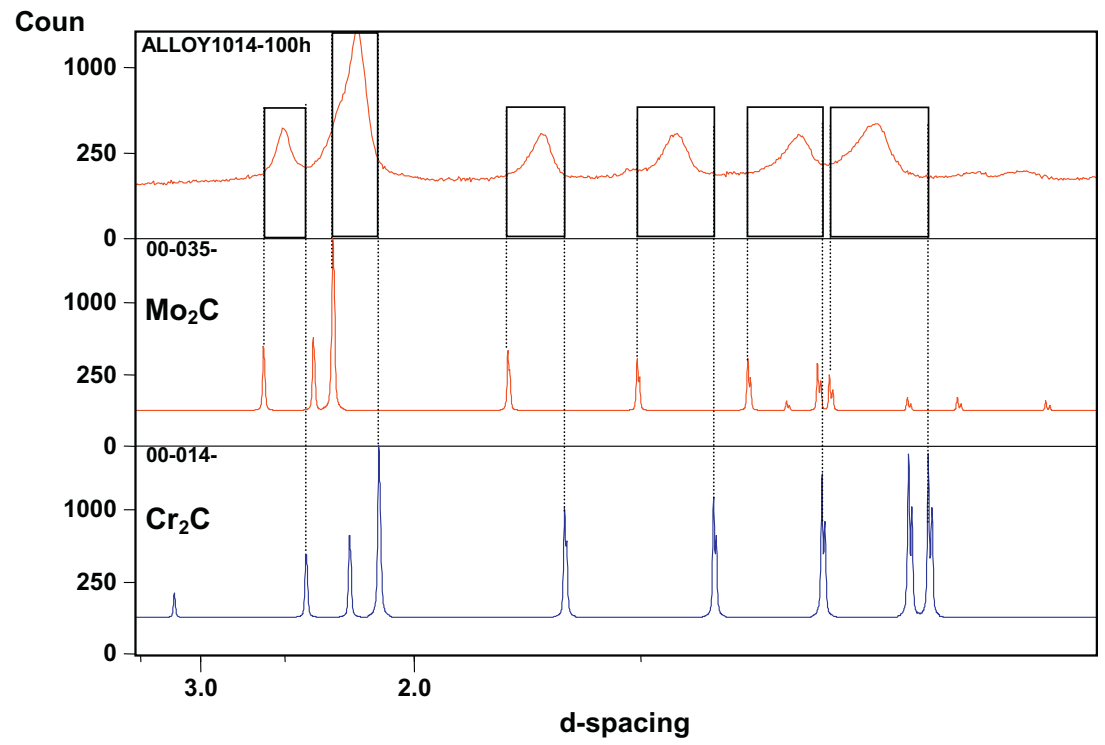

Fig. 3. XRD spectrum for the Alloy 1014 grade tempered for $100 \mathrm{~h}$ at $500{ }^{\circ} \mathrm{C}$ (carbide powder after matrix dissolution). The positions of the peaks correspond to diffraction by hexagonal $(\mathrm{MoCr})_{2} \mathrm{C}$ carbide. 

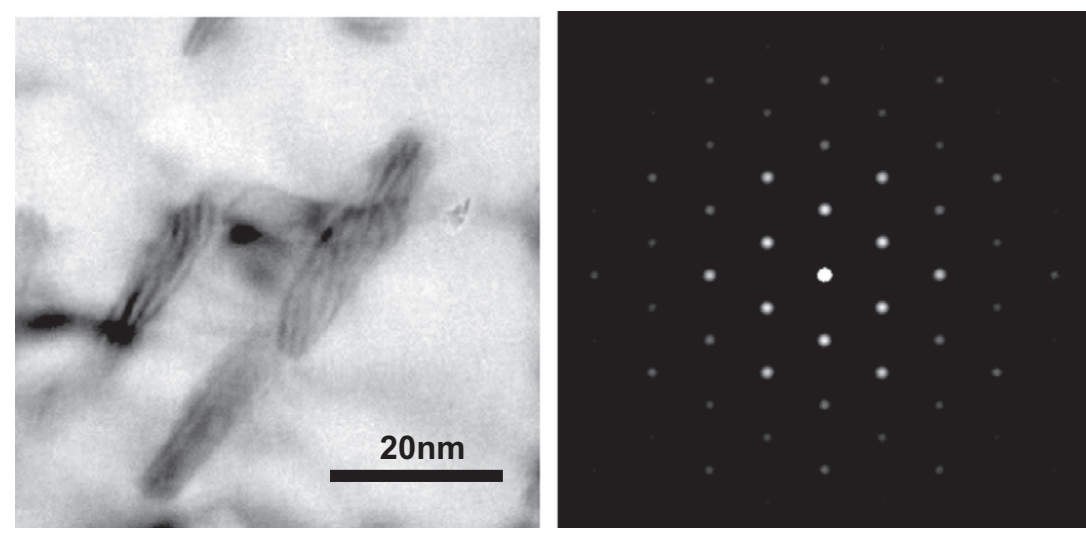

Fig. 4. (Left) Bright field TEM image of $\mathrm{M}_{2} \mathrm{C}$ carbides and (right) the corresponding diffraction pattern for the Alloy1014 grade.

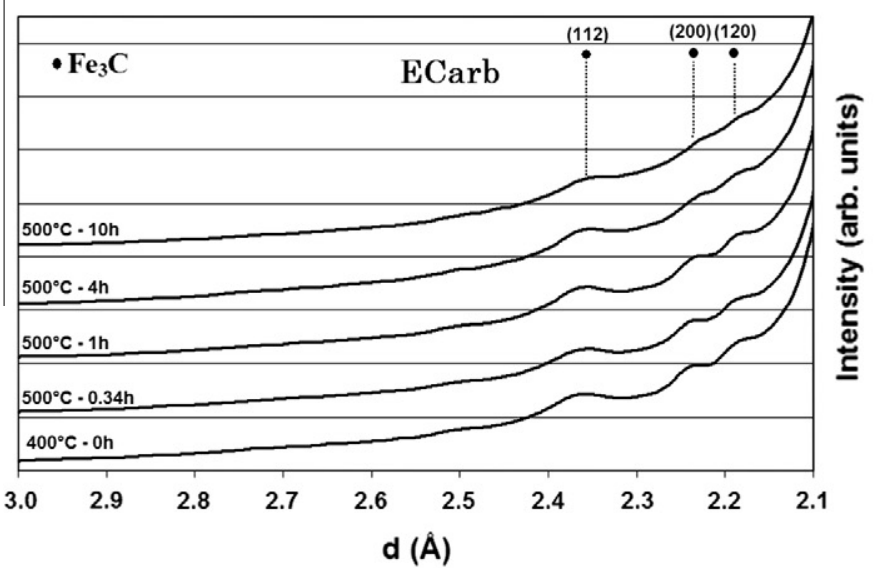

(a)

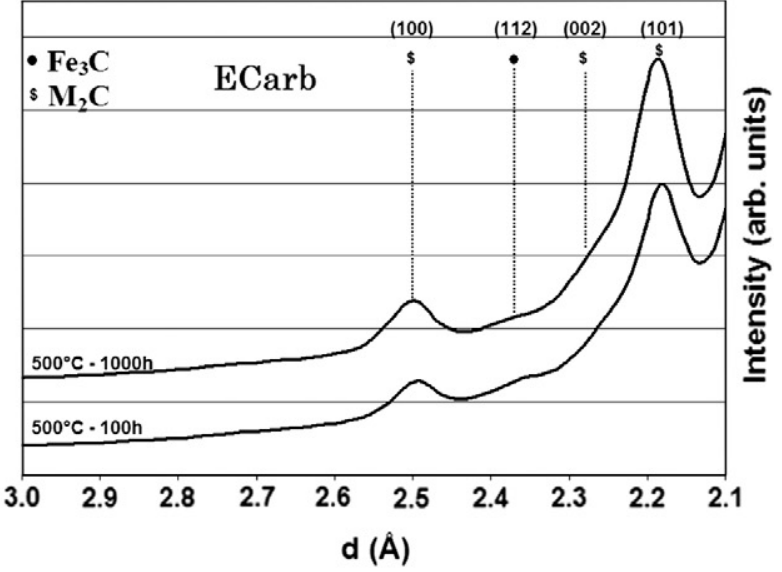

(b)

Fig. 5. Synchrotron XRD spectrum for the Ecarb grade for a simple ramp to $400{ }^{\circ} \mathrm{C}$ and directly back to room temperature and various tempering times at $500{ }^{\circ} \mathrm{C}$ from (a) 0.34 to $10 \mathrm{~h}$ and (b) 100 to $1000 \mathrm{~h}$.

Table 2

Chemical composition (at.\%) of (a) the intermetallic phase, (b) the secondary carbides and (c) the martensitic matrix with tempering time for Alloy1014 grade.

\begin{tabular}{|c|c|c|c|c|c|c|c|c|}
\hline & & Nominal composition & $10 \mathrm{~min}$ & $20 \mathrm{~min}$ & $1 \mathrm{~h}$ & $4 \mathrm{~h}$ & $10 \mathrm{~h}$ & $100 \mathrm{~h}$ \\
\hline \multirow[t]{3}{*}{ (a) } & $\mathrm{Fe}$ & & 58 & 58 & 57 & 51 & 38 & 28 \\
\hline & $\mathrm{Ni}$ & & 24 & 24 & 24 & 28 & 41 & 46 \\
\hline & $\mathrm{Al}$ & & 18 & 18 & 19 & 21 & 21 & 26 \\
\hline \multirow[t]{4}{*}{ (b) } & $\mathrm{C}$ & & & & $13^{\mathrm{a}}$ & $24^{\mathrm{b}}$ & $30^{\mathrm{c}}$ & $32^{\mathrm{d}}$ \\
\hline & $\mathrm{Cr}$ & & & & $10^{\mathrm{a}}$ & $25^{\mathrm{b}}$ & $33^{\mathrm{c}}$ & $39^{\mathrm{d}}$ \\
\hline & Mo & & & & $5^{\mathrm{a}}$ & $12^{\mathrm{b}}$ & $28^{\mathrm{c}}$ & $26^{\mathrm{d}}$ \\
\hline & $\mathrm{Fe}$ & & & & $72^{\mathrm{a}}$ & $38^{\mathrm{b}}$ & $9^{c}$ & $3^{\mathrm{d}}$ \\
\hline \multirow[t]{7}{*}{ (c) } & $\mathrm{C}$ & 1.08 & & & 0.76 & 0.47 & 0.20 & 0.15 \\
\hline & $\mathrm{Fe}$ & 71.1 & & & 71.7 & 75.1 & 74.1 & 77.5 \\
\hline & $\mathrm{Cr}$ & 2.5 & & & 2.2 & 2.1 & 1.6 & 1.0 \\
\hline & Mo & 0.9 & & & 0.9 & 0.6 & 0.6 & 0.2 \\
\hline & Co & 9.5 & & & 9.7 & 9.3 & 10.6 & 10.9 \\
\hline & $\mathrm{Al}$ & 1.8 & & & 1.2 & 0.7 & 0.5 & 0.1 \\
\hline & $\mathrm{Ni}$ & 13.2 & & & 13.3 & 11.8 & 11.8 & 9.5 \\
\hline
\end{tabular}

The experimental conditions are detailed in Danoix et al. [21]

a Clusters.

${ }^{\text {b }}$ Far from the $\mathrm{M}_{2} \mathrm{C}$ stoichiometric composition.

c $\sim \mathrm{M}_{2} \mathrm{C}$.

${ }^{d} \mathrm{M}_{2} \mathrm{C}$. 

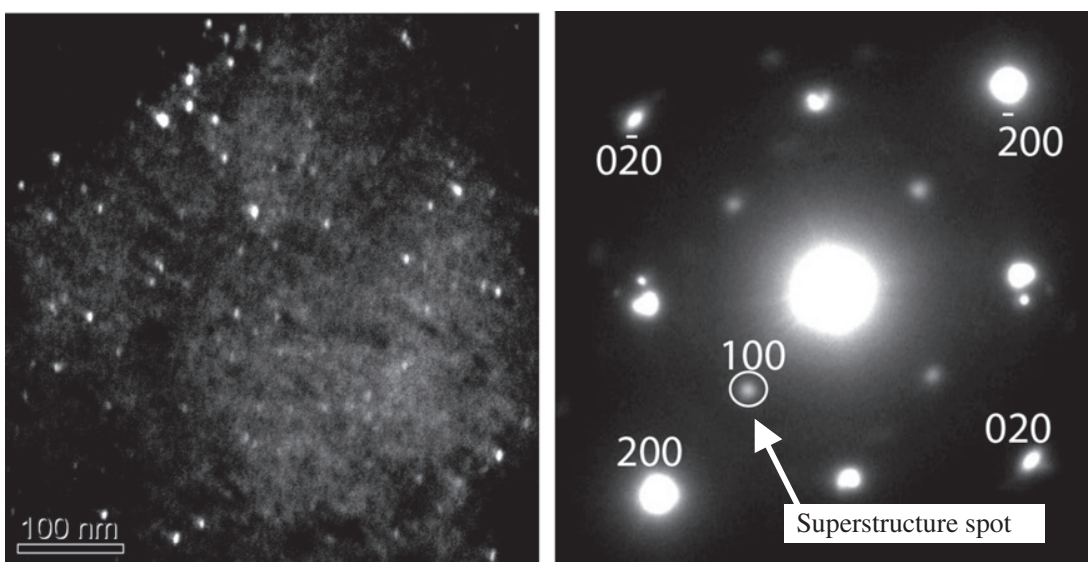

Fig. 6. (Left) Dark field TEM image of $\beta$-NiAl particles and (right) the corresponding diffraction pattern for the Alloy1014 grade.

of iron and chromium were only observed in the Ecarb grade for tempering times (Fig. 5) shorter than $100 \mathrm{~h}$. The main conclusions are given for each grade.

- Ecarb grade. Iron carbides were clearly identified by both TEM observation and synchrotron XRD, whereas hexagonal $\mathrm{M}_{2} \mathrm{C}$ carbides containing chromium and iron were clearly observed for samples tempered for more than 10 h (Fig. 5).

- Einter grade. A large amount of iron was measured by APT analysis in the intermetallic phase in the Einter, Ecofree and Alloy1014 grades (see Table 2 for the results obtained for Alloy1014). Furthermore, very fine $\beta$-NiFeAl-type particles were observed and identified by TEM and SAED for tempering durations of $10 \mathrm{~h}$ and more (Fig. 6). These ordered particles were also observed for shorter tempering durations, although it was not possible to obtain a clear diffraction pattern ( 1 or $2 \mathrm{~nm}$ sized particles with the same structure with very similar parameters compared with the matrix). For longer tempering times $(100 \mathrm{~h})$ it was clearly established that the precipitates were fully coherent with the martensitic matrix, with the relationship $\langle 100\rangle_{\alpha} / /\langle 100\rangle_{\mathrm{NiFeAl}}$.
- Ecofree. Transition $\varepsilon$ carbides were identified in the early stages of precipitation (interrupted tempering). Nevertheless, these particles were unstable, as no iron carbides ( $\varepsilon$ or cementite) were found by XRD analysis after a few hours tempering. Both $\beta$-NiFeAl and $\mathrm{M}_{2} \mathrm{C}$ particles were observed. Each type of precipitate seemed to be in a similar qualitative configuration (number density, shape) as if they had precipitated in a single precipitation specimen.

- Alloy1014. The same conclusions were drawn as for the Ecofree grade concerning iron carbides (Fig. 7). Fully coherent spherical $\beta$-NiFeAl-type particles and semicoherent $\mathrm{M}_{2} \mathrm{C}$ carbides with a Pitsch-Schrader relationship to the matrix were observed using HRTEM (Fig. 8).

The APT technique is particularly crucial in determining the chemical compositions of the particles and matrix accurately (see Table 2). Notably, the local composition near precipitates can also describe the interface partition of alloying elements. Regarding Alloy1014, after a temperature ramp to $200{ }^{\circ} \mathrm{C}, 300{ }^{\circ} \mathrm{C}$ and $400{ }^{\circ} \mathrm{C}$ strong segregation of carbon was observed and the carbon content of the

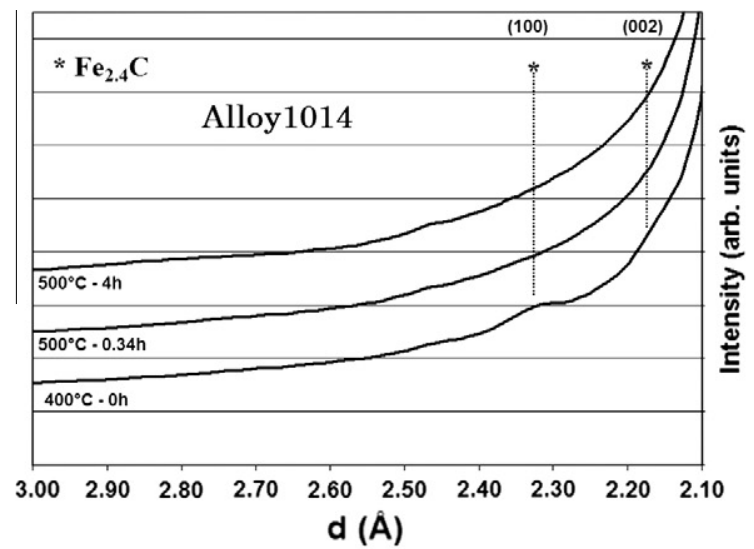

(a)

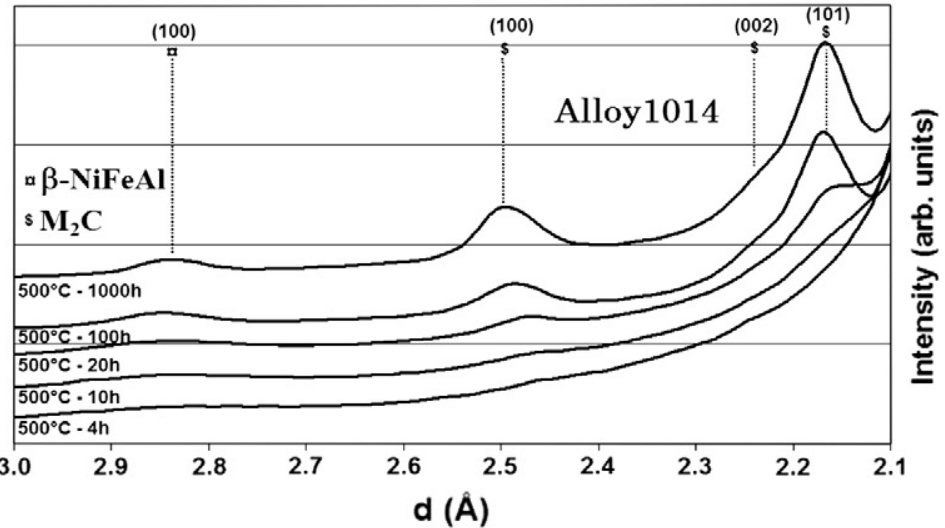

(b)

Fig. 7. Synchrotron XRD spectrum for the Alloy 1014 grade for a simple ramp to $400{ }^{\circ} \mathrm{C}$ and directly back to room temperature and various tempering times at $500^{\circ} \mathrm{C}$ from (a) 0.34 to $4 \mathrm{~h}$ and (b) 4 to $1000 \mathrm{~h}$. 

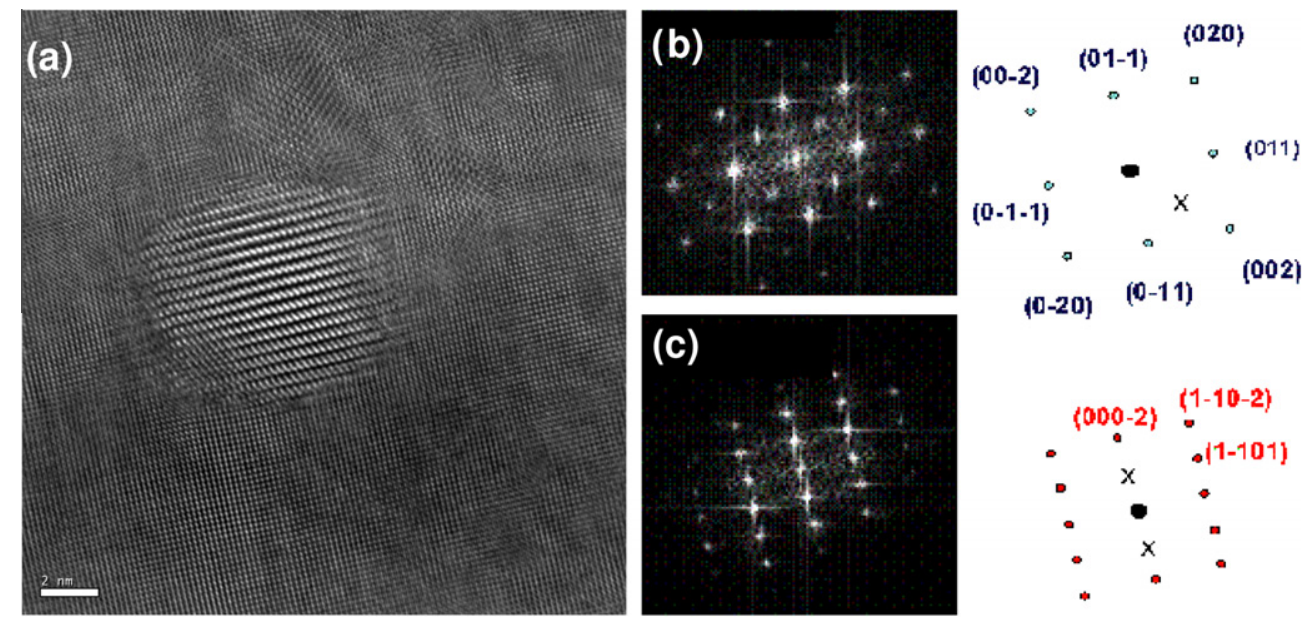

Fig. 8. (a) HRTEM image of a $\mathrm{M}_{2} \mathrm{C}$ carbide and (b, c) the corresponding FFT analysis for (b) the matrix and (c) the carbide.

matrix was about half the nominal composition. Other elements remained in solid solution. This strong local segregation of carbon was due to dislocations inherited from the quench, as has been widely discussed in the literature since the original work of Speich [24]. Molybdenum-chromium $\mathrm{M}_{2} \mathrm{C}$ carbides were not observed (Table 2). After tempering at $500^{\circ} \mathrm{C}$ for $1 \mathrm{~h}$ carbides were still difficult to detect. Indeed, only atomic clusters could be observed after $4 \mathrm{~h}$, with local variations in the carbon as well as chromium and molybdenum contents. After $10 \mathrm{~h}$ or more (Figs. 3, 4, 7 and 8) ( $\mathrm{MoCr})_{2} \mathrm{C}$ particles had clearly precipitated. As far as intermetallic precipitation is concerned, the kinetics was extremely fast, as a ramp to $500{ }^{\circ} \mathrm{C}$ resulted in intense nucleation and growth leading to a volume fraction of $2 \%$. This percentage rose to nearly $5 \%$ after $10 \mathrm{~min}$ tempering (Figs. 9 and 10). Analysing the chemical composition of the intermetallic phases, a large amount of iron was found for each tempering condition. Moreover, aluminium and nickel enrichment with increasing tempering time was observed (Table 2).

For the Ecarb grade, a significant volume fraction of precipitates was measured by SANS after 10 min tempering. The size of nanoparticles for the industrial treatment (10 h tempering) was $1.5 \mathrm{~nm}$ and the corresponding volume fraction reached nearly $1.8 \%$ (the maximum volume frac- tion was $2.7 \%$ ). These particles were clearly identified as being very rich in chromium and molybdenum $\left(\mathrm{M}_{2} \mathrm{C}\right)$. Precipitation of a NiFeAl intermetallic phase was observed for the Einter grade. This precipitation was also identified after 10 min tempering. The mean size of samples tempered for $10 \mathrm{~h}$ was $2 \mathrm{~nm}$ and the corresponding volume fraction was $7.2 \%$, the maximum.

The precipitation kinetics were compared for the two types of precipitates in the different grades. Fig. 10 shows a comparison of the kinetics of $\mathrm{FeNiAl}$ and $\mathrm{M}_{2} \mathrm{C}$ precipitations in the Einter and Ecarb grades. Equivalent radii, volume fractions and number densities were compared. No significant differences in mean radius were observed for tempering durations less than $10 \mathrm{~h}$. At $100 \mathrm{~h}$ the results obtained by SANS and ATP are less relevant because the particles become too large to obtain reasonable measurements by either technique. However, considering the volume fraction of carbides with increasing tempering time two stages could be defined. The first stage led to rapid precipitation. The corresponding volume fraction reached nearly $1 \%$, but without any certainty from these two techniques as to whether this first stage was due to carbon clusters, as suggested by the APT results (see below), or to the precipitation of transition iron carbides. The second stage, leading to a volume fraction close to $3 \%$, was slower and

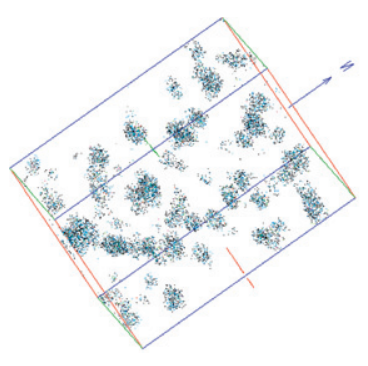

$15 \times 15 \times 23 \mathrm{~nm}^{3}$

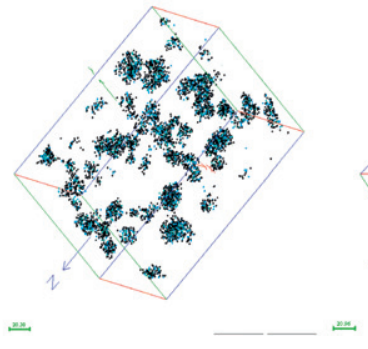

$15 \times 15 \times 23 \mathrm{~nm}^{3}$

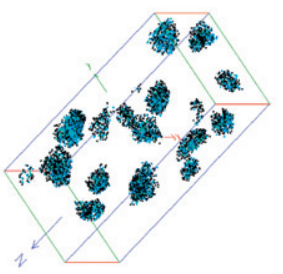

$11 \times 11 \times 23 \mathrm{~nm}^{3}$

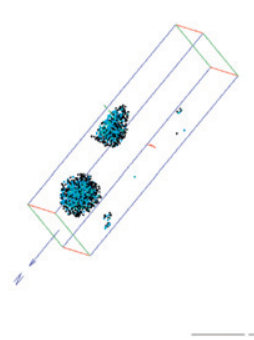

$6 \times 6 \times 23 \mathrm{~nm}^{3}$

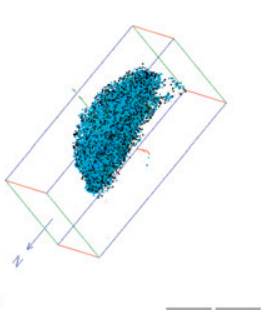

$10 \times 10 \times 23 \mathrm{~nm}^{3}$

Fig. 9. APT analyses of the NiFeAl particles in the Alloy 1014 grade tempered at $500{ }^{\circ} \mathrm{C}$ for $10 \mathrm{~min}$, and $1,4,10$, and $100 \mathrm{~h}$ (from left to right). Individual dots correspond to atoms in $\mathrm{NiFeAl}$ particles. 


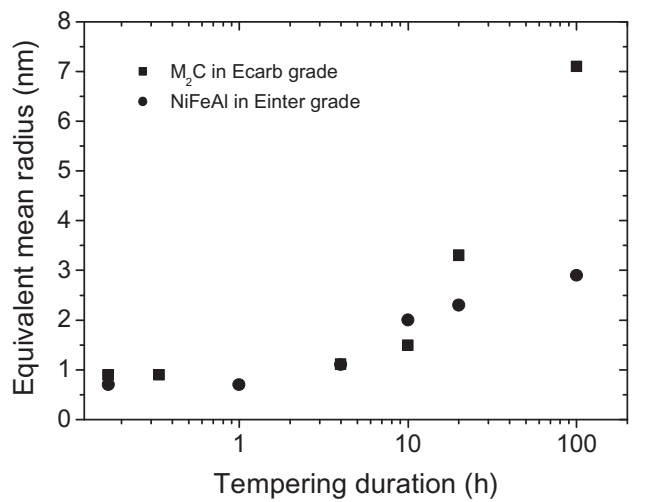

(a)

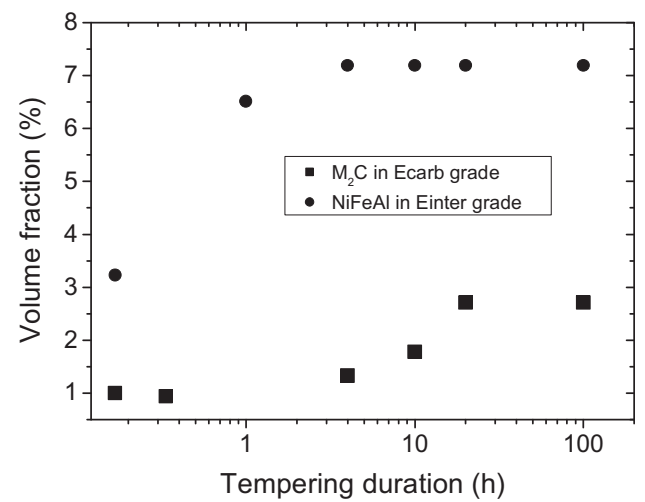

(b)

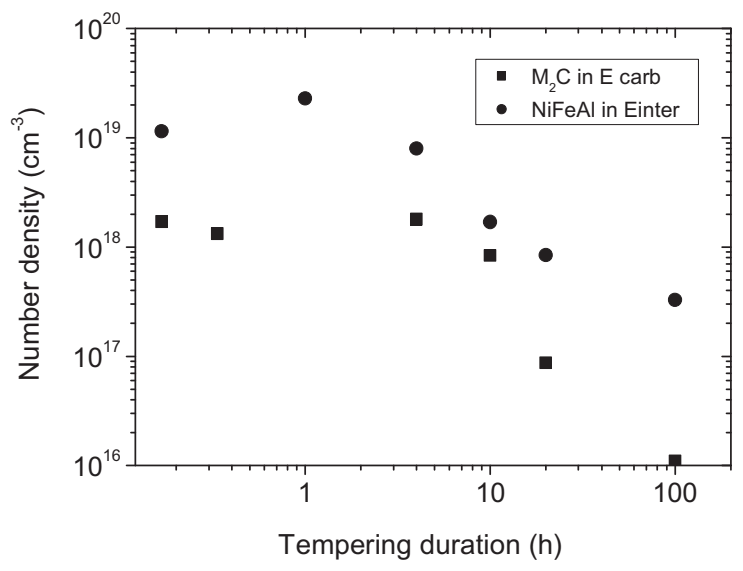

(c)

Fig. 10. Comparison of the kinetics of precipitation of $\mathrm{FeNiAl}$ and $\mathrm{M}_{2} \mathrm{C}$ particles in the Einter and Ecarb grades: (a) equivalent radius; (b) volume fractions; (c) number densities. Data obtained by SANS [18].

was clearly due to the precipitation of molybdenum-chromium $\mathrm{M}_{2} \mathrm{C}$-type secondary carbides. Conversely, the precipitation kinetics of FeNiAl particles seems to be faster than that of carbides (the volume fraction at saturation was reached after a shorter tempering time). The measurements after 10 min tempering already showed a significant volume fraction compared with the saturation value for both carbides and the intermetallic phase, between onethird and half of the saturation value. The first statement that can be made concerning the mechanical resistance is that the tensile strength does not exceed $1450 \mathrm{MPa}$ when only one type of precipitation occurs (grades Ecarb and Einter).

Comparable precipitation kinetics for the two types of precipitate were obtained for the Alloy1014 grade, but with faster growth of the $\mathrm{M}_{2} \mathrm{C}$ carbides compared with the Ecarb grade (Fig. 11). This effect could be due to the cobalt content, which is known to increase the driving force for precipitation by increasing the activity of carbon in ferrite [4,25-27]. In addition, cobalt also increases the activity of molybdenum in ferrite [28]. Due to magnetic interaction, the addition of cobalt to ferrite increases the chemical potential of the alloying elements (Co dramatically increases the Curie temperature). For instance, the solubil-

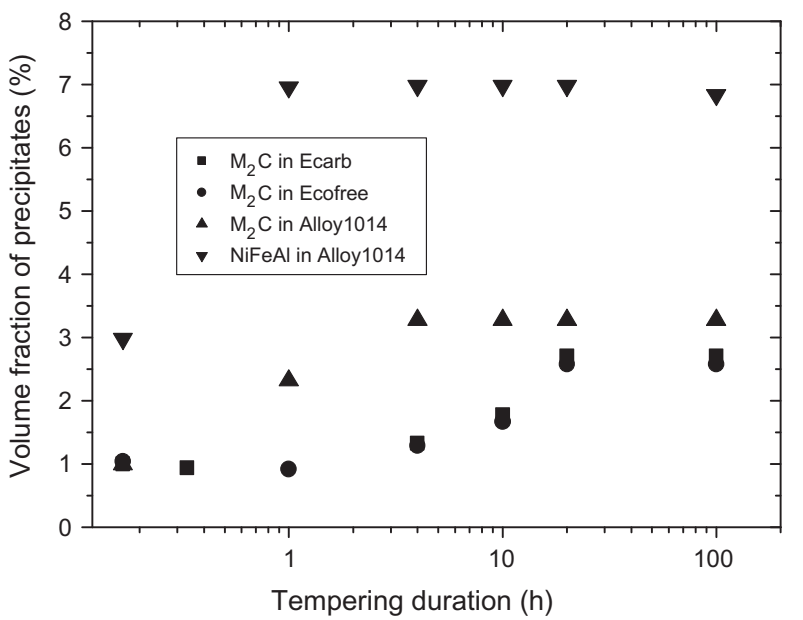

Fig. 11. Volume fractions of $\mathrm{M}_{2} \mathrm{C}$ carbides in the experimental and Alloy1014 grades with tempering duration: comparison with $\mathrm{NiFeAl}$ particles in Alloy1014. Data obtained by SANS [18].

ity of molybdenum in ferrite is greatly decreased as the cobalt content increased. This second effect of cobalt also contributes to enhance the precipitation of a denser distribution of $\mathrm{M}_{2} \mathrm{C}$ carbides. Fig. 11 shows the kinetics of 


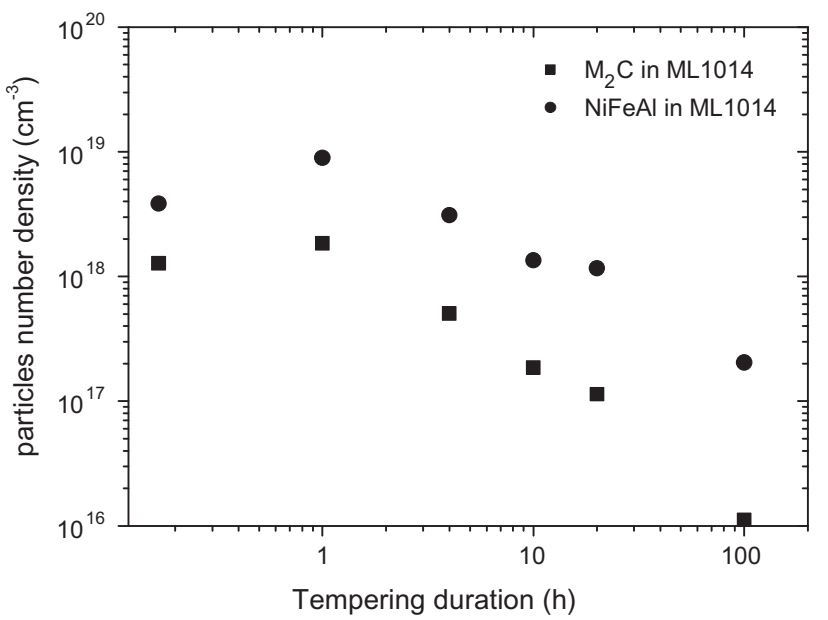

Fig. 12. Comparison of the $\mathrm{M}_{2} \mathrm{C}$ and $\mathrm{NiFeAl}$ number densities in the Alloy1014 grade with tempering duration. Data obtained by SANS [18].

precipitation of $\mathrm{M}_{2} \mathrm{C}$ carbide in the grades Ecarb, Ecofree and alloy1014. A clear shift towards short tempering times was observed for Alloy1014 compared with the other two. Fig. 12 shows the evolution of particle number densities vs. tempering time. A factor of 10 gap was found between the number densities of intermetallic and carbide particles for Alloy1014. In addition to the difference in the number density of particles, interaction between the precipitates and dislocations could be another relevant hypothesis to explain the very high strength of double precipitation steels. Depending on the particles considered, as well as the crystallographic relationship with the matrix, the mechanisms involved in the interaction (bypassing or shearing) are critical and have been identified by several authors $[29,30]$. Conversely, the spatial distribution of particles within the martensitic matrix (homogeneous or heterogeneous), which also influences the deformation micromechanisms, still needs to be precisely analysed.

\subsection{Distribution of precipitates within the martensitic matrix}

TEM observations were mainly devoted to analysing the homogeneity of the particle distribution within the martensitic matrix, which was mainly dependent on the sites of nucleation of the different types of precipitation.
Regarding the Ecarb grade, dislocations are preferential sites for carbide nucleation, as different authors have already shown, and thus only a relatively homogeneous distribution can be obtained. Moreover, depending on the chemical composition of the steel, mainly the carbon content, molybdenum-chromium carbide precipitation may be influenced by the partial dissolution of iron carbides, either by in situ nucleation or by releasing alloying elements and carbon into the matrix. Thus the distribution of $\mathrm{M}_{2} \mathrm{C}$ precipitates is strongly linked to the metastable cementite precipitates. The cementite particles are quite coarse, and heterogeneously distributed (partly precipitating at the lath boundary), therefore limiting the toughness of many ultrahigh-strength martensitic steels [10,31]. Conversely, TEM observations of the Einter grade (Fig. 13) show numerous intermetallic $\mathrm{NiFeAl}$ particles that are very homogeneously distributed in the martensitic matrix. This result can be easily explained by the low carbon content, exactly as in maraging steels, and the subsequent low density of dislocations generated during quenching. Consequently, the high number density of NiFeAl precipitates is presumed to nucleate homogeneously, inducing more uniformly distributed spherical precipitates. When both populations are involved in the strengthening (Ecofree and Alloy1014) the distribution of intermetallic particles seems to be similar to that found in the Einter grade. The general configuration of $\mathrm{M}_{2} \mathrm{C}$ carbides observed by TEM for long tempering times does not seem to be significantly modified either.

The FIM analyses were in total agreement with the TEM observations [21]. Indeed, it has been shown in a previous work [21] that the precipitation of an intermetallic second phase affects the nucleation mechanism and the spatial distribution of the secondary hardening carbides. The nucleation turns from heterogeneous on dislocations to heterogeneous on $\mathrm{NiAl}$ particles, resulting in a homogeneous spatial distribution of the carbides in the matrix. On the other hand, cementite particles were not detected in the Alloy1014 and the Ecofree grades. The tempering process seems to be divided into three stages, as described in Fig. 14: carbon segregation on dislocations produced during quenching, then the formation of carbon- and chromium-enriched clusters and, finally, precipitation of
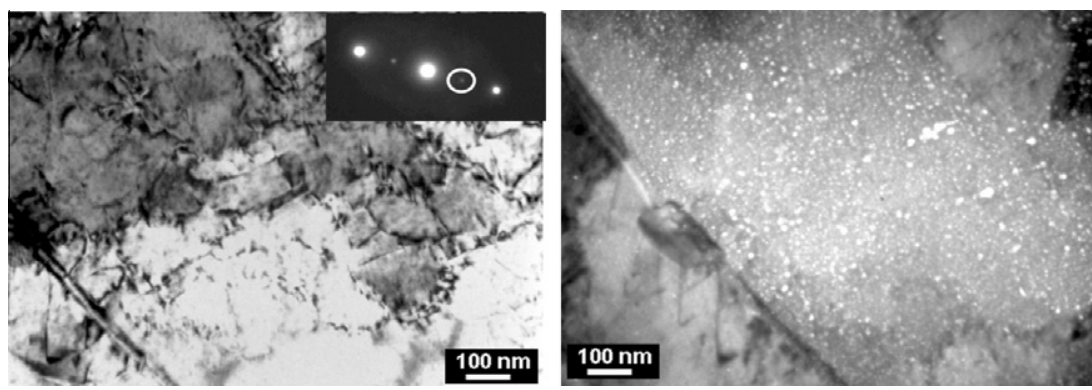

Fig. 13. (Left) Bright field and (right) dark field TEM images and the corresponding diffraction patterns showing the distribution of NiFeAl particles in the Einter grade (the same martensitic lath with a shift to the right (about $300 \mathrm{~nm}$ ) between the bright field and dark field images). 


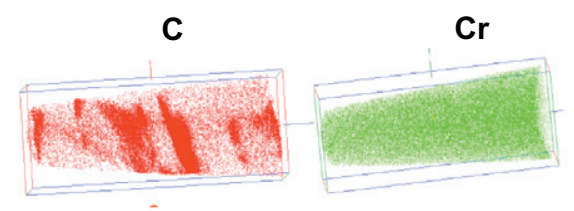

(a) after few seconds

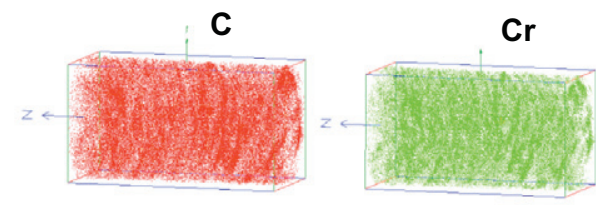

(b) after few minutes

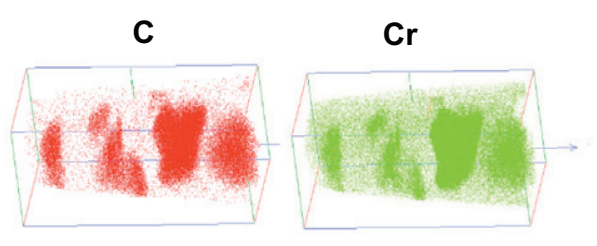

(c) after 100 hours

Fig. 14. Evolution of the carbon and chromium distributions within the martensitic matrix with tempering time at $500{ }^{\circ} \mathrm{C}$ for the Alloy 1014 steel $(3 \mathrm{DFIM}$ analysis, box dimensions approximately $50 \times 50 \times 100 \mathrm{~nm}$ ).

secondary alloyed carbides. As absolutely no iron carbides are involved in the precipitation sequence and as a better spatial distribution of carbon is observed during the second stage (cluster formation), the mechanism involved is very far from the conventional sequence, which includes the formation of cementite.

\section{Discussion: developing cementite-free steels, a relevant route to improving the strength-toughness balance}

The mechanical properties of steels containing a single precipitate of carbides or intermetallic compounds are well known. The yield strength of steels containing secondary carbides can be very high, but at the expense of ductility, Charpy impact energy and fracture toughness. This balance is partly due to the high number density of secondary carbides, the mode of crossing of particles by dislocations and the distribution of precipitates. The heterogeneous distribution of coarse cementite and secondary carbides contributes significantly to limiting the toughness. On the other hand, the yield stress of maraging steels containing $\beta-\mathrm{NiFeAl}$ precipitates remains close to $1300-1500 \mathrm{MPa}$ at room temperature, whereas toughness may reach values comparable with or higher than those of conventional steels. Therefore, the general assumption that the extremely high number density of NiFeAl precipitates (compared with secondary carbides) predominantly contributes to steel strengthening in double precipitation steels is not relevant. This hypothesis would suggest that every precipitate constitutes an equivalent obstacle to dislocations, which is definitely not correct. This set of properties is connected to shearing of the coherent particles by dislocations, as well as the much more homogeneous distribution of the precipitates. Thus it becomes evident that a combination of the advantages of the two types of precipitate would be beneficial to the balance of properties.

From the mechanical properties obtained compared with those reported in the literature for steels hardened by molybdenum-chromium $\mathrm{M}_{2} \mathrm{C}$ carbides (AF1410 and
Aermet) and by $\mathrm{NiAl}$ particles (maraging steels) it can be deduced that $\mathrm{M}_{2} \mathrm{C}$ precipitation is crucial to achieving a mechanical resistance above $2000 \mathrm{MPa}$, as it is impossible to obtain this level with the intermetallic phase alone. As a consequence, the excellent mechanical strength obtained in the double precipitation grades is due to the more homogeneous distribution of molybdenum carbides in the martensitic matrix. Although the mechanism is not fully identified, particularly during the early stages of tempering, the intermetallic phase, which precipitates with fast kinetics, influences the secondary carbide distribution. The term "assisted precipitation" seems most appropriate, as the mechanism is completely different from the precipitation of carbides of the supersaturated alloying elements in the bulk, due to dislocations produced during quenching, or from unstable iron carbide particles (in situ nucleation).

The precursor steels to the GE1014 and Alloy1014 grades developed for aeronautical applications (for instance AF1410 and Aermet 100, 310 and 340) and which contained a single precipitate of molybdenum carbides also achieved better fracture toughness. For these grades the analyses also showed the absence of cementite particles during the tempering process $[4,6]$, thus removing brittle crack paths. Therefore, the suppression of cementite precipitation in the tempering sequence should not be related merely to intermetallic phase co-precipitation, with a few other options being investigated. This will be discussed in the next paragraph. Finally, the main conclusion here is that developing cementite-free steels seems to be one of the most relevant and effective routes to improving the strength-toughness balance. Creating a short path in the conventional precipitation sequence is quite an old idea but it has still been insufficiently explored.

\section{How to eliminate iron carbide precipitation during the tempering process?}

The first suggestion is based on the considerable work of Speich [24,31] and consists of limiting the carbon content. 
From the literature available at the time of publication the usual description of tempering suggested that the martensite obtained after quenching could be regarded as a carbon supersaturated ferrite. The carbon is almost immediately released during tempering of a ferrite, which recovers stability from a thermodynamic point of view. Thus, iron carbide formation was thought to be almost instantaneous, since the limit of solubility of carbon in $\alpha$-iron given by the phase diagram is negligible. Speich showed that it was necessary to take into account the density of dislocations resulting from quenching. Indeed, carbon atoms tend to diffuse to the dislocations (pipe diffusion) provided that the carbon concentration is not too high (less than $0.2 \mathrm{wt} . \%$ for tempering temperatures lower than $150{ }^{\circ} \mathrm{C}$ ). It was then possible to specify the difference between tempered martensite and ferrite, since precipitation is absent for steels with moderate carbon contents, as almost all carbon atoms are segregated in the Cottrell atmosphere [24,32]. At higher temperatures the thermally activated rearrangement of dislocations [33,34], which causes the release of carbon, results in the precipitation of iron carbides in plain carbon steels. In alloyed steels the rapid precipitation of very small intermetallic particles would be favourable to maintaining the structure of dislocations, and therefore carbon segregation, at higher tempering temperatures. The direct precipitation of $\mathrm{M}_{2} \mathrm{C}$ carbides, without precipitation of iron carbides, can also be supported, taking into consideration the influence of alloying elements, such as silicon and aluminium, which delay cementite precipitation at higher tempering temperatures $[35,36]$. This effect can be so strong for an aluminium content of around $1 \mathrm{wt} . \%$ that cementite is absent from the sequence, and the $\mathrm{M}_{2} \mathrm{C}$ carbide directly nucleates at the dislocation sites, as already suggested by Olson [4] for AF1410 steel.

The role of cobalt in Alloy1014 steel is not clearly understood, as no experimental results (TEM, SANS or APT) showed significant differences in the microstructure of grades containing cobalt from those that did not. From the literature [4,25-28] the addition of cobalt should result in retention of the dislocation substructure at higher temperatures, thus limiting recovery and inducing the formation of a finer dispersion of the alloy carbides heterogeneously nucleated at dislocation sites. Moreover, since cobalt raises the activity of both carbon and molybdenum in ferrite, decreasing the solubility of the alloy carbide, supersaturation increased and, thus, the nucleation rate was enhanced. This description from the literature is in agreement with SANS results, as a clear shift in the kinetics of carbides at shorter tempering times was observed for Alloy1014, compared with the Ecofree grades. Cobalt addition also contributes to suppressing the precipitation of cementite particles by introducing an extremely dense and rapid precipitation of fine particles early in the tempering process.

Results obtained by SANS and APT showed that the kinetics of precipitation of $\mathrm{NiFeAl}$ particles are very fast. This is in agreement with the literature, which reported very rapid nucleation (less than $1 \mathrm{~min}$ at $500{ }^{\circ} \mathrm{C}$ [3]) due to nickel and aluminium supersaturation in the martensitic structure. Furthermore, the APT analyses revealed that the molybdenum and chromium contents in the intermetallic compound were negligible. Consequently, rejection of these two elements from the particle seems to be a reasonable hypothesis, which is supported by the literature [23] on a steel containing a higher content of chromium (13 wt.\%). In fact, the reported effect of $\mathrm{Mo}$ and $\mathrm{Cr}$ segregation at the interface is still a subject of debate, and the release of alloying elements (Mo and $\mathrm{Cr}$ ) at the NiFeAl particle interface has not been experimentally observed in every study [37]. However, the in situ nucleation of $\mathrm{M}_{2} \mathrm{C}$ carbides from the intermetallic particles, which has been clearly shown [21], may be explained by a mechanical interaction instead of a chemical mechanism. The local stress field and the associated distortion induced by coherent NiFeAl precipitation may also influence the nucleation of $\mathrm{M}_{2} \mathrm{C}$ carbides. The essential difference in the precipitation sequence, compared with conventional steels, lies in direct $\mathrm{M}_{2} \mathrm{C}$ nucleation starting from $\mathrm{NiFeAl}$ particles. As previously mentioned, cementite is a coarse, heterogeneously distributed phase which is not very effective in limiting steel recovery during tempering, notably because the poor stability increases the temperature. In the case of double precipitation steels the first strong influence of the rapid, intensive and homogeneous nucleation of intermetallic particles is that it limits martensite recovery during tempering by reducing the decrease in dislocation density. The homogeneous distribution of secondary carbides, associated with a higher density of dislocations, results in a huge increase in the mechanical resistance, which reaches $2300 \mathrm{MPa}$ for specific heat treatment conditions.

\section{Conclusion}

To improve the balance between mechanical strength and toughness, double precipitation steels containing nanometric $(\mathrm{MoCr})_{2} \mathrm{C}$ and $\mathrm{NiFeAl}$ secondary precipitates were developed. In order to explain the advantageous balance of properties obtained, two experimental grades were also manufactured with a single precipitate of carbides and intermetallic compounds, respectively. Volume fractions, number densities, chemical compositions and the distribution of particles in the martensitic matrix were determined according to the tempering duration at $500{ }^{\circ} \mathrm{C}$ using SANS, APT, TEM and XRD experiments. The main results can be summarised as follows.

- The excellent mechanical properties are mainly due to a more homogeneous distribution of $(\mathrm{MoCr})_{2} \mathrm{C}$ carbides in the martensitic matrix, combined with very rapid precipitation of a high number density of NiFeAl particles, limiting recovery of the steel during tempering. The sufficient toughness is explained by the removal of heterogeneously distributed and coarse iron carbides. 
- The interaction between the two types of particle is due to rapid precipitation of the intermetallic compound, which affects the nucleation of carbides. Indeed, the intermetallic particles become the main nucleation site of secondary carbides, instead of nucleation generally influenced by dislocations and iron carbides. This mechanism can be supported by both carbon segregation on dislocations and the high aluminium content, which causes a shift in the precipitation kinetics of cementite for longer tempering durations. The addition of cobalt contributes to raising the mechanical strength of double precipitation steels by increasing the carbide nucleation rate and then introducing an extremely dense and rapid precipitation of fine particles early in the tempering process.

- The most relevant way to modify the mechanical strength/toughness balance in martensitic steels is to avoid cementite precipitation during the tempering process. This goal can be achieved by introducing extremely rapid and fine precipitation in the early stages of tempering. Other intermetallic phases, as well as copper, are now being studied. In the same way various carbideforming elements are also being investigated, particularly for high temperature applications.

\section{Acknowledgement}

The French National Agency is gratefully acknowledged for its financial support (ANR-05-RNMP-08).

\section{References}

[1] Garrison WM, Strychor R. Metall Trans 1988;19A:3103.

[2] Hamano R. Metall Trans 1993;24A:127.

[3] Erlach SD, Leitner H, Bischof M, Clemens H, Danoix F, Lemarchand D, et al. Mater Sci Eng A 2006;429:96.

[4] Olson GB. In: Olson GB, Azrin M, Wright ES, editors. Proceedings of the 34th Sagamore Army materials research conference Innovations in Ultra-High Strength Steel Technology, Lake George, NY, 1987; 1990, p. 3.

[5] Olson GB. Adv Mater Process 1997;152:72.

[6] Carinci GM, Olson GB, Liddle JA, Chang L, Smith GDW. In: Olson GB, Azrin M, Wright ES, editors. Proceedings of the 34th Sagamore
Army materials conference Innovations in Ultra-High Strength Steel Technology, Lake George, NY, 1987; 1990, p. 179.

[7] Ayer R, Machmeier PM. Metall Trans 1993;24A:1943.

[8] Novotny PM. US patent application 0113931A1; 2007.

[9] Rhoads MA, Raymond EL, Garrison WM. US patent 5,393,488; 1995.

[10] Garrison WM, Rhoads MA. Trans Indian Inst Met 1996;49:151.

[11] Erlach SD, Danoix F, Leitner H, Auger P, Siller I, Clemens H. Surf Interf Anal 2007;39:213.

[12] Zhang Z, Delagnes D, Bernhart G. Int J Fatigue 2002;24:635.

[13] Souki I, Delagnes D, Lours P. Proc Eng 2011;10:631.

[14] Kim C, Biss V, Hosford WF. Metall Trans 1982;13A:185.

[15] Cotton JP. In: Lindner P, Zemb T, editors. Neutron, X-ray and light scattering: introduction to an investigative tool for colloidal and polymeric systems. Amsterdam: North Holland; 1991. p. 19.

[16] Delagnes D, Lamesle P, Mathon MH, Mebarki N, Levaillant C. Mater Sci Eng A 2005;394:435.

[17] Mathon MH, Barbu A, Dunstetter F, Maury F, Lorenzelli N, De Novion CH. J Nucl Mater 1997;245:224.

[18] Perrut M, Mathon MH, Delagnes D. J Mater Sci 2012;47:1920.

[19] Vurpillot F, Gilbert B, Deconihout B. Surf Interf Anal 2007;39:273.

[20] Da Costa G, Vurpillot F, Bostel A, Deconihout B. Rev Sci Instrum 2005;76(013304):1.

[21] Danoix F, Danoix R, Akre J, Grellier A, Delagnes D. J Microscopy 2011;244:305.

[22] Hochanadel PW, Robino CV, Edwards GR, Cieslak MJ. Metall Mater Trans 1994;25A:789.

[23] Ping DH, Ohnuma M, Hirakawa Y, Kadoya Y, Hono K. Mater Sci Eng A 2005;394:285.

[24] Speich GR. Trans TMS-AIME 1969;245:2553.

[25] Chandhok VK, Hirth JP, Dulis EJ. Trans TMS-AIME 1962;224:858.

[26] Yang HR, Lee KB, Kwon H. Metall Mater Trans 2001;32A:1659.

[27] Garrison WM. ISIJ Int 2006;46:782.

[28] Rong W, Andrén HO, Wisell H, Dunlop GL. Acta Metall Mater 1992;40:1727.

[29] Taillard R, Pineau A. Mater Sci Eng 1982;56:219.

[30] Schrober M, Lerchbacher Ch, Eidenberger E, Staron P, Clemens H, Leitner H. Intermetallics 2010;18:1553.

[31] Speich GR, Dabkowski DS, Porter LF. Metall Trans 1973;4:303.

[32] Chang L, Barnard SJ, Smith GDW. In: Krauss G, Repas PE, editors. Fundamentals of aging and tempering in bainitic and martensitic steel products. Warrendale (PA): ISS-AIME; 1992. p. 19.

[33] Pesicka J, Kuzel R, Dronhofer A, Eggeler G. Acta Mater 2003;51:4847.

[34] Mebarki N, Delagnes D, Lamesle P, Delmas F, Levaillant C. Mater Sci Eng A 2004;387-389:171.

[35] Leslie WC, Rauch GC. Metall Trans 1978;9A:343.

[36] Arbuzov MP, Kotlyar BI, Sologub NI. Izvestiya VUZ Chernaya Metallurgya 1978;8:647.

[37] Guo Z, Sha W, Vaumousse D. Acta Mater 2003;51:101. 